\title{
Genome-Wide Associations and Transcriptional Profiling Reveal ROS Regulation as One Underlying Mechanism of Sheath Blight Resistance in Rice
}

\author{
Eula Gems Oreiro, ${ }^{1,+}$ Earlyn Kate Grimares, ${ }^{1,2}$ Genelou Atienza-Grande, ${ }^{1,2}$ Ian Lorenzo Quibod, ${ }^{1}$ \\ Veronica Roman-Reyna, ${ }^{1}$ and Ricardo Oliva ${ }^{1,+}$ \\ ${ }^{1}$ Rice Breeding Platform, International Rice Research Institute, DAPO Box 7777, Metro Manila, Philippines \\ ${ }^{2}$ Institute of Weed Science, Entomology and Plant Pathology, College of Agriculture and Food Science, University of the \\ Philippines, Los Baños, Laguna, Philippines
}

Accepted 18 September 2019.

\begin{abstract}
Rice sheath blight, caused by the necrotrophic fungus Rhizoctonia solani Kühn, continues to be an important and challenging rice disease worldwide. Here, we used genome-wide association studies over a high-density rice array to facilitate the identification of potential novel genes and quantitative trait loci related to sheath blight resistance. We identified multiple regions that significantly associated with independent disease components in chromosomes 1,4 , and 11 under controlled condition. In particular, we investigated $q L N 11^{28}$, a quantitative trait locus enriched with defense-related genes that reduce disease lesions in a near-isogenic line. RNA profiling of the line carrying $q L N 11^{28}$ showed a number of differentially expressed genes related to the reactive oxygen species (ROS)redox pathway. Histochemical staining revealed less ROS accumulation on the resistant line, suggesting efficient ROS deregulation that delays pathogen colonization. The detection of genomic regions controlling multiple mechanisms of resistance to sheath blight will provide tools to design effective breeding interventions in rice.
\end{abstract}

Keywords: complex disease, genomewide association study (GWAS), quantitative trait loci (QTLs), reactive oxygen species (ROS), Rhizoctonia solani, rice sheath blight

Rice (Oryza sativa L.) is an important agricultural crop in the developing world and is the staple food of billions of people. To meet the growing rice demand, genetic improvement needs to target a number of biotic constraints such as fungal disease. Sheath blight $(\mathrm{ShB})$, caused by the soilborne necrotrophic pathogen Rhizoctonia solani Kühn, is one of the most destructive fungal diseases worldwide, with an estimated yield loss of 5 to $10 \%$ (Savary et al. 2012). The disease initially occurs on the leaf sheath when directly in contact with floating

${ }^{\dagger}$ Corresponding authors: E. G. Oreiro; e.oreiro@irri.org and R. Oliva; r.oliva@irri.org

Funding: Support was provided by the Global Rice Science Partnership.

*The $\boldsymbol{e}$-Xtra logo stands for "electronic extra" and indicates that four supplementary figures and eight supplementary tables are published online.

The author(s) declare no conflict of interest.

๑) 2020 The American Phytopathological Society sclerotial bodies. Symptoms of ShB under field conditions appear in the form of circular, oblong, or ellipsoid lesions with greenish-gray, water-soaked spots. These lesions eventually coalesce and encompass leaf sheaths and stems with irregular dark borders as they mature (Ou 1985). Temperature, humidity, and plant morphological traits, including plant height and heading date, are among the environmental factors that can influence the development of ShB symptoms in the rice paddy (Hossain et al. 2014; Pinson et al. 2005; Srinivasachary et al. 2013).

Complete resistance has not been identified yet in any wild or cultivated rice accession (Srinivasachary et al. 2010; Zeng et al. 2015). This is probably because rice cultivars have an extensive variation of susceptibility levels to $\mathrm{ShB}$, which appears to be controlled by many minor genes (Pinson et al. 2005; Srinivasachary et al. 2010; Zou et al. 2000). Although the molecular mechanism underlying the host-pathogen interaction remains unclear (Jia et al. 2012; Li et al. 1995; Pinson et al. 2005; Sharma and Teng 1990; Srinivasachary et al. 2010; Zeng et al. 2015; Zou et al. 2000), some of the pathways associated with resistance to necrotrophic fungi appear to involve the suppression of abscisic acid signaling and the regulation of reactive oxygen species (ROS) (Asselbergh et al. 2007). ROS, in particular, seems to have a dual function because it triggers plant basal defense responses with biotrophic and hemibiotrophic pathogens while enhancing virulence with necrotrophs.

The variability in disease measurements between field and controlled conditions is yet another factor that contributes to hinder the improvement of ShB resistance (Jia et al. 2012). In addition to disease severity measurement, some authors suggested using alternative disease parameters as well as a combination of field and laboratory assessments to determine possible sources of resistance to ShB (Lore et al. 2013; Srinivasachary et al. 2013; Willocquet et al. 2011; Zeng et al. 2015). Most of what is known about quantitative trait loci (QTLs) on $\mathrm{ShB}$ disease is based on the conventional mapping of the biparental population: recombinant inbred lines, double haploids, F2 progenies, or backcross-derived populations (Pinson et al. 2005; Taguchi-Shiobara et al. 2013; Yadav et al. 2015; Zeng et al. 2015; Zhu et al. 2014). The biparental mapping approach is usually labor intensive and produces minimal recombination events, resulting in fewer closely linked markers useful for marker-assisted breeding (Myles et al. 2009). Through advances in high-throughput genotyping technologies, genome-wide association studies (GWAS) have emerged as a 
complementary tool for dissecting complex genetic traits on plants using a high-resolution method. This approach has been particularly useful in studying important traits that show complex interaction such as flowering time, grain size, disease resistance, and abiotic stress tolerance (Bandillo et al. 2013; Begum et al. 2015; Crowell et al. 2016; McCouch et al. 2016; Pasam et al. 2012; Schneider et al. 2016; Vuong et al. 2015; Wang et al. 2014; Wen et al. 2014). GWAS overcomes the limitations of biparental mapping because it relies on historical recombination events within a genetically diverse panel to assess the nonrandom association of alleles providing information into the genetic architecture of the trait (Korte and Farlow 2013; Pasam et al. 2012; Zhao et al. 2014).

In general terms, several of the mapping studies that describe QTLs for ShB used limited numbers of markers or colocalized with genes related to plant morphology (Zeng et al. 2015). In this study, we used GWAS to associate a high-density rice array (HDRA) with three disease components. We identified multiple genomic regions that contribute to $\mathrm{ShB}$ resistance and have no linkage to morphological traits or plant growth. We dissected the effect of a major GWAS signal in chromosome 11 using transcriptional profiling of a near-isogenic line where ROS accumulation showed a role in regulating the $\mathrm{ShB}$ resistance mechanism. A subset of rice accessions was also tested under microfield condition to assess the role of the environment in disease development. To our knowledge, this is the first time wherein HDRA was used to identify genomic regions linked to $\mathrm{ShB}$ resistance.

\section{RESULTS}

\section{ShB development and plant growth.}

To investigate the effect of plant growth on the phenotypic assessment of $\mathrm{ShB}$, we screened a random set of rice accessions using a detached tiller assay (DTA). Disease symptoms were observed at 7 days postinoculation (dpi), when the pathogen was able to produce multiple lesions and colonize the topmost leaf collar up to the base of the plant (Fig. 1A). The data collected on 10 random accessions showed significant variation in each of the three disease components, indicating different levels of susceptibility (Fig. 1B). Even though selected accessions (Supplementary Table S1) showed different growth rates, no significant correlation was observed between length of culm (LC) and any of the three disease components; namely, lesion number (LN), maximum lesion length (MLL), and vertical sheath colonization (VSC) $(r=-0.14,-0.22$, and -0.05 , respectively).

Resistance to ShB shows variation in disease components.

Several reports suggest that members of the rice indica varietal group may be enriched with genetic factors contributing to ShB resistance (Jia et al. 2012; Srinivasachary et al. 2010; Zuo et al. 2008). To identify unexploited sources of resistance, we screened 228 indica rice accessions (Supplementary Table S1) and observed a wide range of resistance responses for each disease component. LN ranged from 2.67 to 22.0, MLL ranged from 9.5 to $53.0 \mathrm{~mm}$, and VSC ranged from 20.67 to $232.2 \mathrm{~mm}$. Pearson correlation coefficients between disease components measured in DTA indicated high correlations among LN, MLL, and VSC (Supplementary Fig. S1). The correlation was highest between LN and VSC $(r=0.90, P<2.2 \mathrm{e}-16)$ followed by MLL with VSC $(r=0.72, P<2.2 \mathrm{e}-16)$ and LN with MLL $(r=0.62$, $P<2.2 \mathrm{e}-16)$. As expected, LC was least correlated with $\mathrm{LN}$, MLL, and VSC ( $r=0.18,0.15$, and 0.17 , respectively). However, some of the lines that were characterized as moderately resistant to one component were found to be susceptible to a different component. Based on the phylogenetic analysis of the indica rice accessions, six genetic clusters were identified (Fig. 2A). Genetic diversity within the subgroup of indica was probably due to geographical origin, ancestry, and historic breeding activities. Interestingly, none of the disease components correlated with genetic clusters. Overall, the observed distribution of phenotypes ranged from susceptible to resistant, with 5 accessions characterized as resistant, 9 as moderately resistant, 64 as moderately susceptible, and 150 as susceptible.

\section{Environmental factors influence ShB resistance stability.}

Previous studies highlighted the impact of environmental factors on ShB assessments (Pinson et al. 2005; Srinivasachary et al. 2010; Willocquet et al. 2011; Zeng et al. 2015). Plant

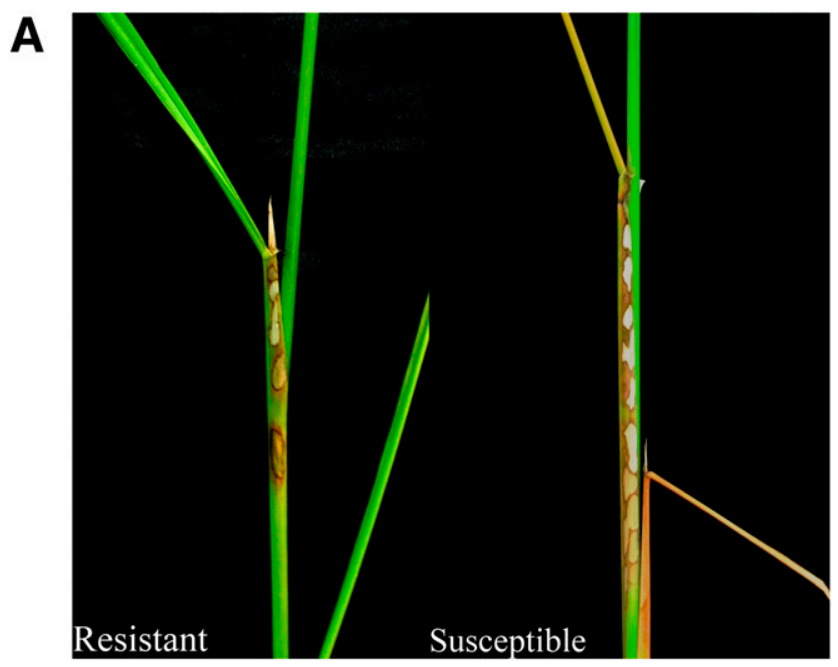

B
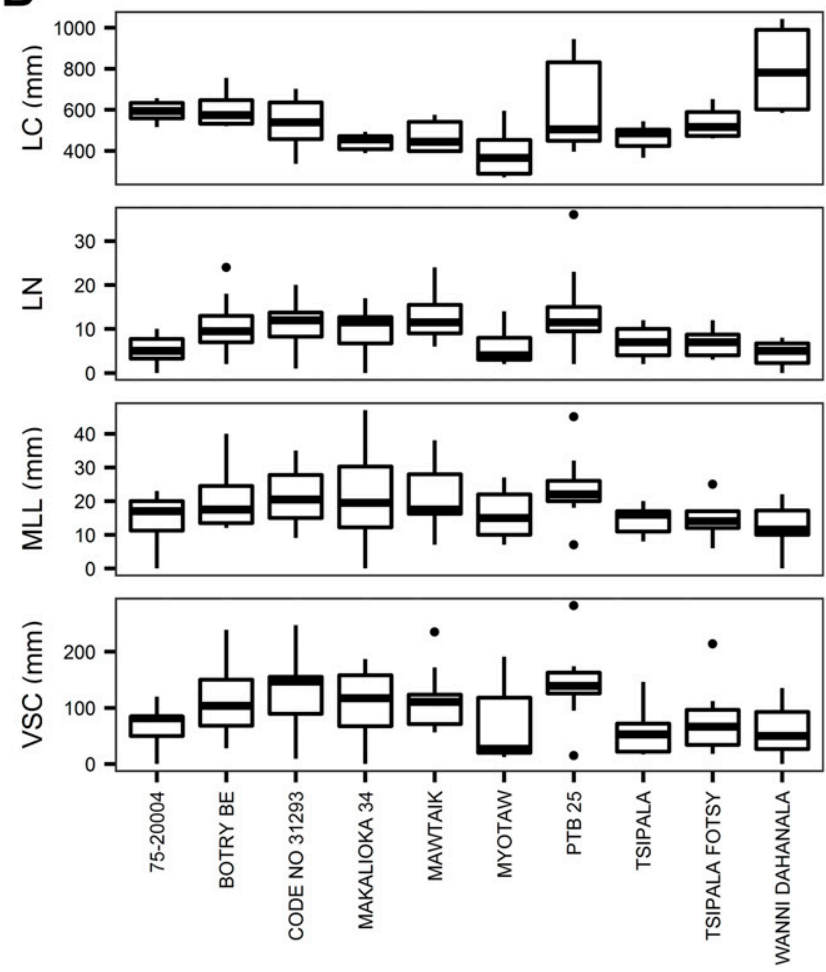

Fig. 1. Phenotypic assessment of sheath blight disease in rice lines with different growing rates. A, Disease lesions observed in resistant and susceptible genotypes 7 days postinoculation. B, Boxplot graphs representing three disease components on rice lines with different growing rates: lesion number (LN), maximum lesion length (MLL), and vertical sheath colonization (VSC). The length of culm (LC) was also measured. 
microenvironment, variable humidity, and temperature fluctuations may affect the spread of the pathogen in the field. To assess the phenotypic stability of $\mathrm{ShB}$ resistance under microfield conditions, we used 17 accessions that were previously characterized as resistant to moderately resistant $(n=8)$ and susceptible $(n=9)$ based on DTA (Supplementary Table S2). Interestingly, only four of the eight resistant to moderately resistant accessions showed consistent reaction under microfield condition when compared with the resistant control (Fig. 2B). In particular, the accessions Gie57 and Liu Xu showed good levels of resistance across disease components when evaluated under controlled and microfield conditions whereas the Da Nuo and Vellai Seenetti accessions obtained intermediate reactions in the latter condition. The rest of the accessions were indistinguishable from the susceptible control when exposed to microfield condition (Fig. 2B).

\section{Genome-wide associations identify potential regions controlling $\mathrm{ShB}$ resistance.}

GWAS in rice has been successfully used as a platform to dissect loci in complex diseases and agricultural traits. To dissect the genetic basis of resistance to $\mathrm{ShB}$, we used a HDRA containing 700,000 single nucleotide polymorphisms (SNPs) to perform GWAS on the phenotype of 228 rice accessions. We identified two major regions with significant SNPs and three other regions with building up signals that may also be carrying genes
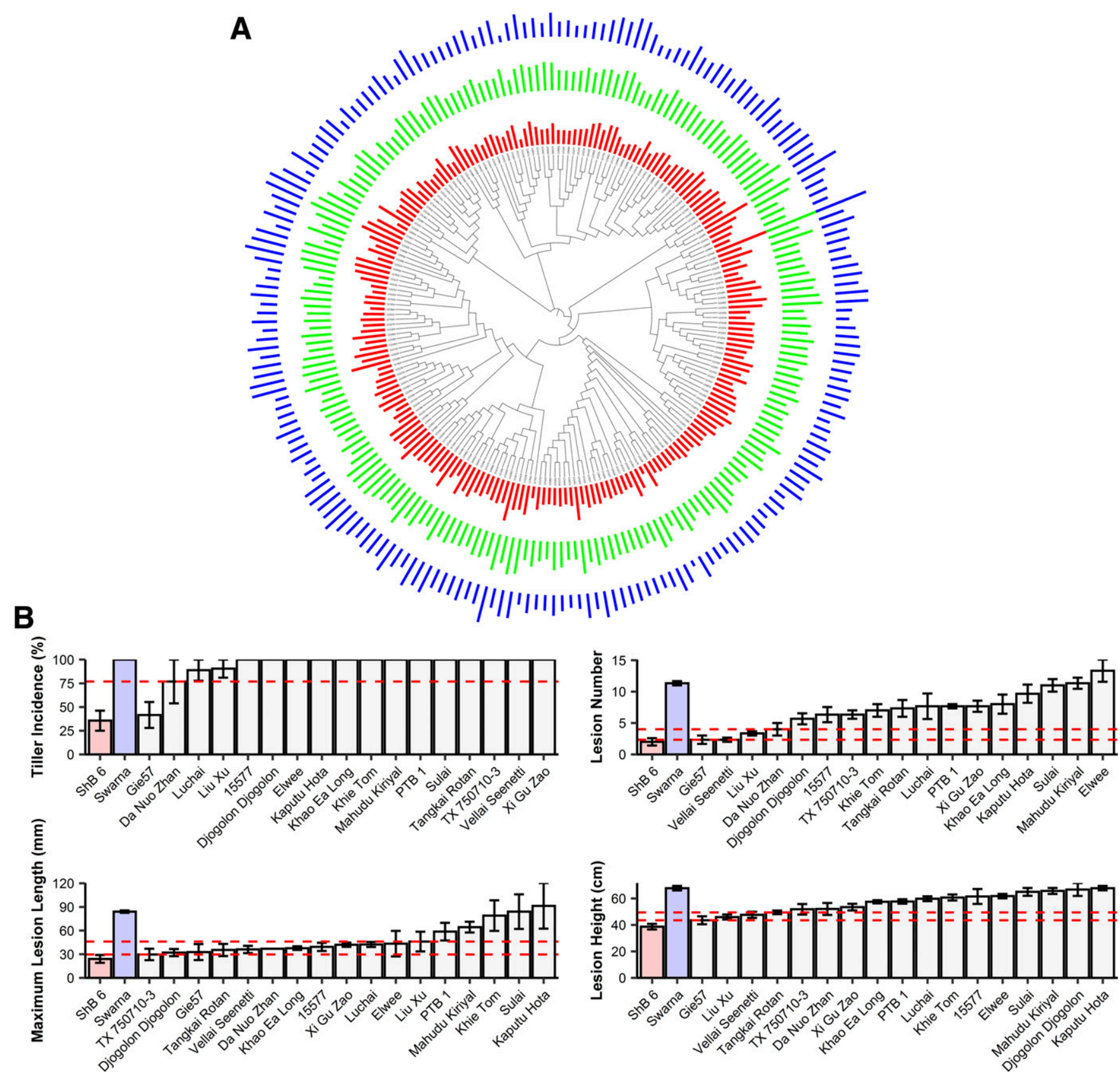

Fig. 2. Sheath blight resistance variation among disease components. A, The inner circle represents the phylogenetic tree of 228 indica rice accessions and the outer circles correspond to sheath blight (ShB) disease components, where bars represent the percentage values for each component. Lesion number (LN), maximum lesion length (MLL), and vertical sheath colonization (VSC) are color-coded in red, green, and blue, respectively. B, Microfield assessment of ShB disease components on 17 selected rice accessions. Bars represent the mean value of three replications per experiment. Red and blue bars indicate the resistant and susceptible checks, respectively. Rice accessions on and between red dashed lines showed some levels of resistance to ShB. Error bars indicate the standard errors of the mean in tiller incidence, LN, MLL, and lesion height, assessed 21 days after inoculation. 
controlling ShB resistance (Table 1; Supplementary Table S3). The two major signals in LN and MLL were represented by 22 significant SNPs whereas, for VSC, the three building signals showed 16 SNPs close to significance (Supplementary Table S4). All these SNPs were distributed in chromosomes 1, 4, and 11 (Fig. 3; Supplementary Table S4). LN obtained a total of 14 significant SNP markers clustered at $q L N 11^{28}$. For MLL, highly significant markers were identified and clustered on chromosome 11 at $q M L L 11^{14}$. LN and MLL regions have phenotypic variance of approximately $17 \%$ (Table 1). For VSC, the regions with building signals were distributed in three chromosomes $\left(q V S C 1^{05}\right.$, $q V S C 4^{01}$, and $q V S C 11^{28}$ ) (Supplementary Table S3) and have phenotypic variation ranging from 8.96 to $11.55 \%$, with a total of 16 candidate SNPs (Supplementary Table S4). Interestingly, a similar signal was detected in chromosome $11(28 \mathrm{Mb})$ using LN and VSC. The colocalized signals of LN and VSC consistently had significant correlation $(r=0.90, P<2.2 \mathrm{e}-16)$ among the disease components. The expected and observed probabilities of association of SNPs for each disease component were shown through quantile-quantile (QQ) plots (Fig. 3).

\section{Linkage disequilibrium and haplotype blocks association.}

Linkage disequilibrium (LD), which is critical for mapping complex traits in GWAS, usually shows variation among rice accessions with different genetic backgrounds (Mather et al. 2007). The LD relationship among loci was determined by calculating the distribution of correlation coefficients $\left(r^{2}\right)$ between SNPs located at different physical distances from each chromosome. As expected, the $r^{2}$ value declined as the physical distance between the loci increased. LD decay varied among all regions, ranging from approximately 100 to $200 \mathrm{~kb}$ (Supplementary Fig. S2). On the same note, previous studies have shown that cultivated rice has a similar range of LD decay (Huang et al. 2010; McNally et al. 2009; Xu et al. 2016). The five putative regions were further subjected to haplotype analysis using Haploview and different LD patterns were observed as indicative of the conservation of the genetic identity (Stracke et al. 2007). Some SNP regions belonged to large LD blocks with high and significant $D^{\prime}$ values whereas most of the SNPs were found in small LD blocks. We detected approximately 17 to 27 haplotype blocks in each genomic region (Supplementary Fig. S3). Using these criteria, in total, 255 genes were selected in the five regions (Supplementary Table S5). However, among all LD patterns, only $q L N 11^{28}$ harbored most significant haplotype blocks enriched with biotic response genes involved in defense (Supplementary Fig. S4; Supplementary Table S5). SNPs that are all in high LD are all inherited together and, therefore, represent each other with high heritability. Thus, this analysis helps to increase the allelic resolution of candidate genomic regions and to detect historical recombination and joint inheritance in the same chromosomal block (Qian et al. 2017).

\section{$q L N 11^{28}$ contributes to disease resistance.}

We noticed that the $q L N 11^{28}$ signal colocalized with a QTL containing multiple resistance genes, including the bacterial blight gene $\mathrm{Xa}$ 4 . Therefore, we hypothesized that transferring a region similar to $q L N 11^{28}$ would contribute to reduce $\mathrm{ShB}$ severity to some extent. To further validate this hypothesis, we infected IRBB4, an IR24 near-isogenic line carrying the Xa4 region, using DTA. Interestingly, IRBB4 showed scientifically lower scores in most of the disease components compared with IR24 (Fig. 4A). The average scores on LN of IRBB4 were approximately half those of IR24 and the VSC was approximately $64 \mathrm{~mm}$ in length. Disease values of IRBB4 and the resistant check (ShB6) were statistically the same while scores of IR24 were highest across all disease components and were incomparable with the susceptible check (Swarna) based on analysis of variance (ANOVA) (Supplementary Table S6). These results suggest that $\mathrm{Xa} 4$ or other immunity-related genes within $q L N 11^{28}$ might contribute to reduce ShB disease.

\section{$q L N 11^{28}$ activates innate immunity and potentially modulates oxidative burst.}

To investigate the mechanism behind $q L N 11^{28}$, we identified differentially expressed genes (DEGs) between susceptible and resistant lines at 6,12 , and $24 \mathrm{~h}$ postinoculation (hpi). Overall, we found 277 genes that were differentially expressed between IR24 and IRBB4 (Fig. 4B; Supplementary Table S7). Most of the DEGs identified using indica or japonica reference genomes appear to be involved in stress response, hormone metabolism, carbohydrate and amino acids biosynthesis, and modulation of respiratory burst (Fig. 4B). Almost $90 \%$ of the DEGs were upregulated in the resistant line at 12 and $24 \mathrm{hpi}$, which is consistent with an active response in the resistant line. Photosynthesis, lipid metabolism, stress response, and ROS deprivation genes were activated in the line carrying $q L N 11^{28}$ as early as $12 \mathrm{hpi}$. After $24 \mathrm{~h}$, genes related to degradation and recycling of ROS were still active in the resistant line. We further examined the interactions among the 277 experimental DEGs and the cofunctional networks predicted across the five candidate signals. The analysis identified 71 DEGs as priority candidates, suggesting indirect pathways related to stress response (Supplementary Table S8).

To identify genes that contribute to $\mathrm{ShB}$ resistance within the $q L N 11^{28}$ region, we looked closely to the DEGs within the IR64 scaffold_653 which contain the same insertion sequence present in IRBB4. Among the 10 genes spanning this region, we only found three immunity-related genes showing differential expression between resistant and susceptible lines. Os11g0695000, encoding for a leucine-rich protein kinase, and $O s 11 \mathrm{~g} 0695800$, encoding for a serine/threonine protein kinase, appeared to have a basal expression in the resistant line. Meanwhile, Os 1 1 06694125, encoding a wall-associated receptor kinase, showed induction in IRBB4 as early as 6 hpi. To validate this finding, we measured the transcript accumulation of the three genes using quantitative reverse transcriptionpolymerase chain reaction (RT-qPCR) and found similar results. In particular, the Os11g0694125 and Os11g0695000 candidate genes were not induced in IR24 at all time points (Fig. 4C). The activation of innate immunity-related genes may suggest that the resistant line is able to respond faster to pathogen attack.

To investigate whether the resistant line is able to modulate products of the oxidative burst, we measured ROS accumulation during $R$. solani colonization using histochemical staining. We did not find any visible signal of ROS after 6 or 12 hpi (data not shown) but ROS accumulation appeared to build up in IR24

Table 1. Significant genomic regions associated with different disease components controlling sheath blight resistance analyzed in mixed linear model

\begin{tabular}{|c|c|c|c|c|c|}
\hline Disease component & Quantitative trait locus & Chromosome & Physical position (Mb) & $P$ value & $R^{2}(\%)^{\mathbf{a}}$ \\
\hline Lesion number & $q L N 11^{28}$ & 11 & $28,012,384$ & 7.08E-09 & 17.057 \\
\hline Maximum lesion length & $q M L L 11^{14}$ & 11 & $14,460,338$ & 2.13E-09 & 17.636 \\
\hline
\end{tabular}

${ }^{a}$ Percentage of variation explained by marker $\left(R^{2}\right)$. 
and IRBB4 lines after 24 hpi (Fig. 4D). The same observation was reported by Ghosh et al. (2017), where the pathogen seems to avoid host recognition. A significant difference was observed in ROS accumulation after $48 \mathrm{hpi}$, where the resistant line showed less stained area $(3.05 \pm 0.32)$ compared with the susceptible line $(6.15 \pm 0.36)(P<0.05)$. After $72 \mathrm{~h}$, the trend appeared to be similar but there were no statistical differences among the inoculated lines (Fig. 4E). Using RT-qPCR, we detected transcript accumulation on three candidate genes related to ROS deregulation (Fig. 4F). As expected, the pattern of expression varied considerably among these genes at different time points. Expression of ROS genes was highly induced in the

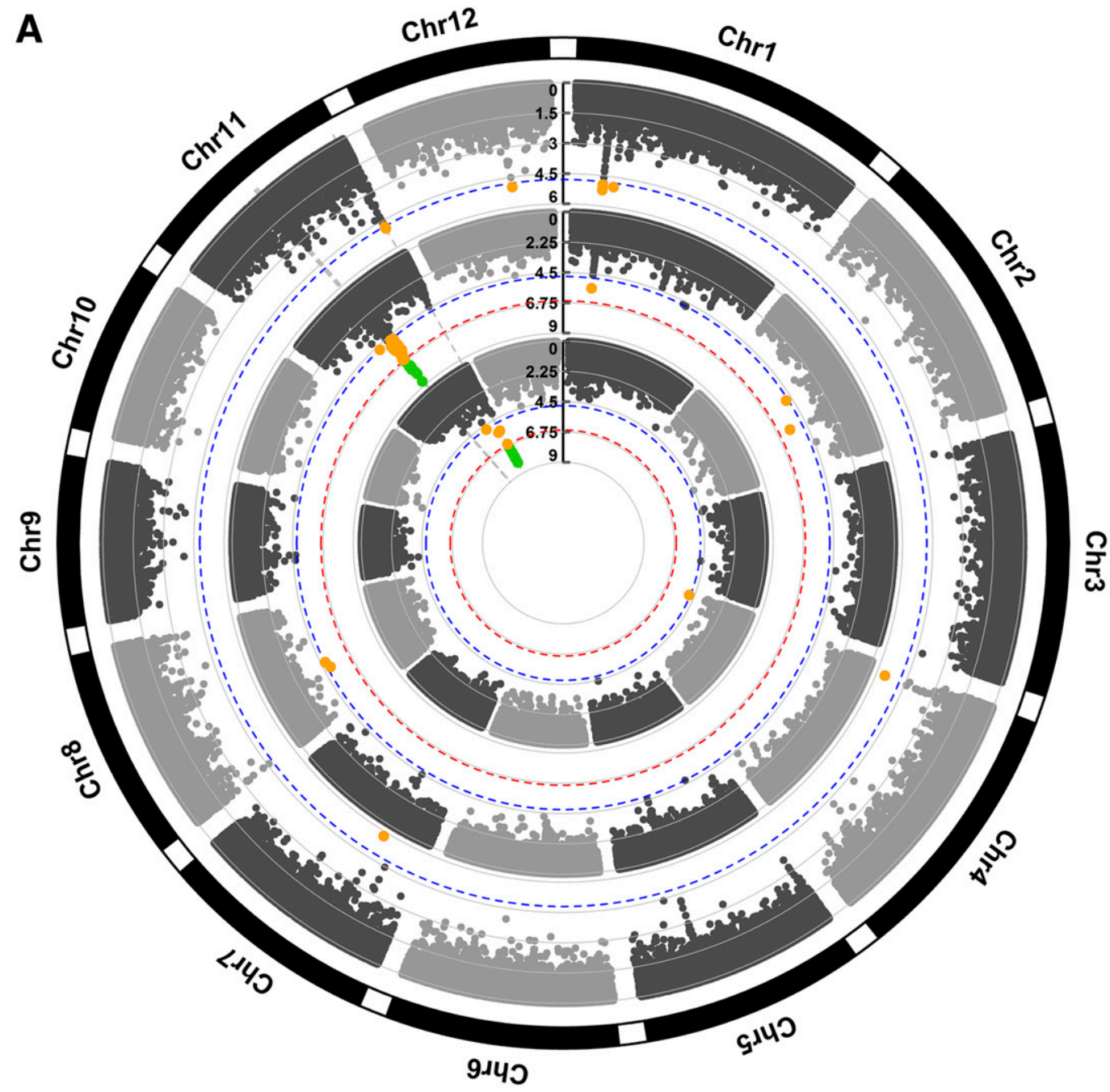

B
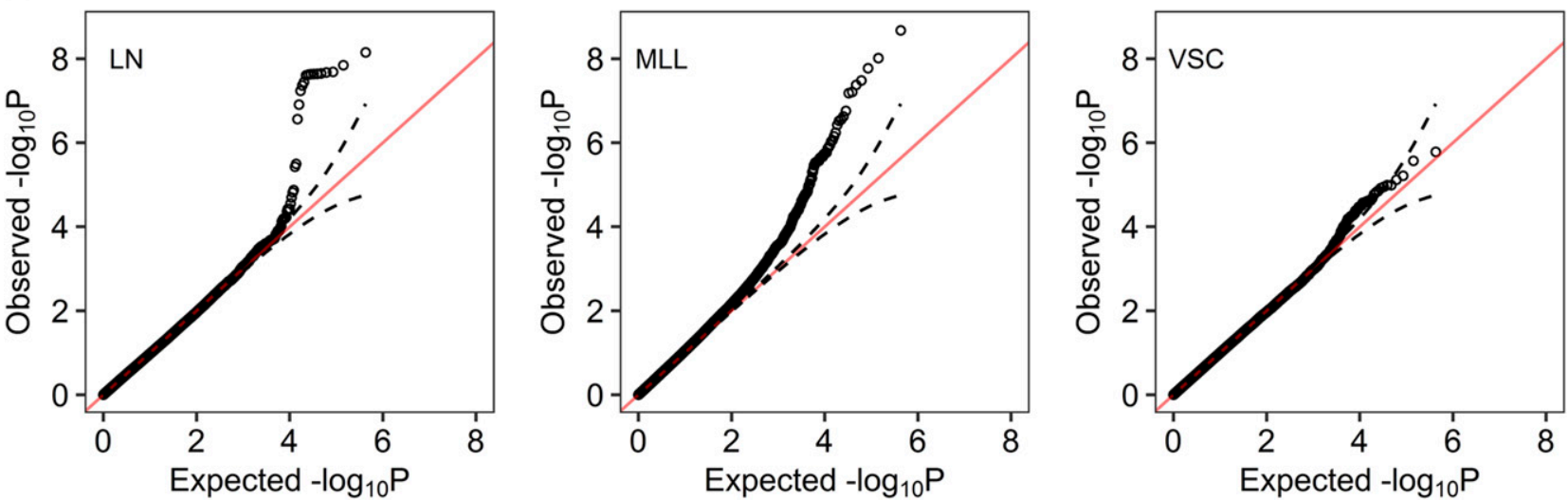

Fig. 3. High-density marker association for sheath blight resistance based on a mixed linear model. A, A circular Manhattan plot shows the associations of the 12 chromosome (Chr) single nucleotide polymorphisms (SNPs) to B, the three disease components: lesion number $(\mathrm{LN})=$ outer circle, maximum lesion length $(\mathrm{MLL})=$ middle circle, and vertical sheath colonization $(\mathrm{VSC})=$ inner circle and its corresponding quantile-quantile plot. Each dot represents a single SNP. Green dots are significant SNPs with a threshold of $-\log _{10} P>6.63$ while orange dots are SNPs with building signals of $-\log _{10} P>4.5$. 

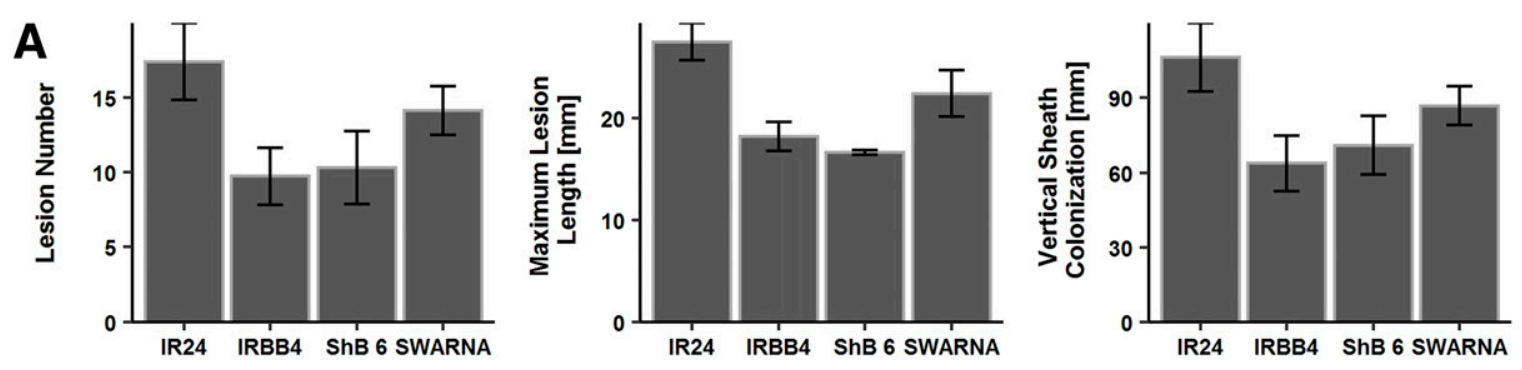

B
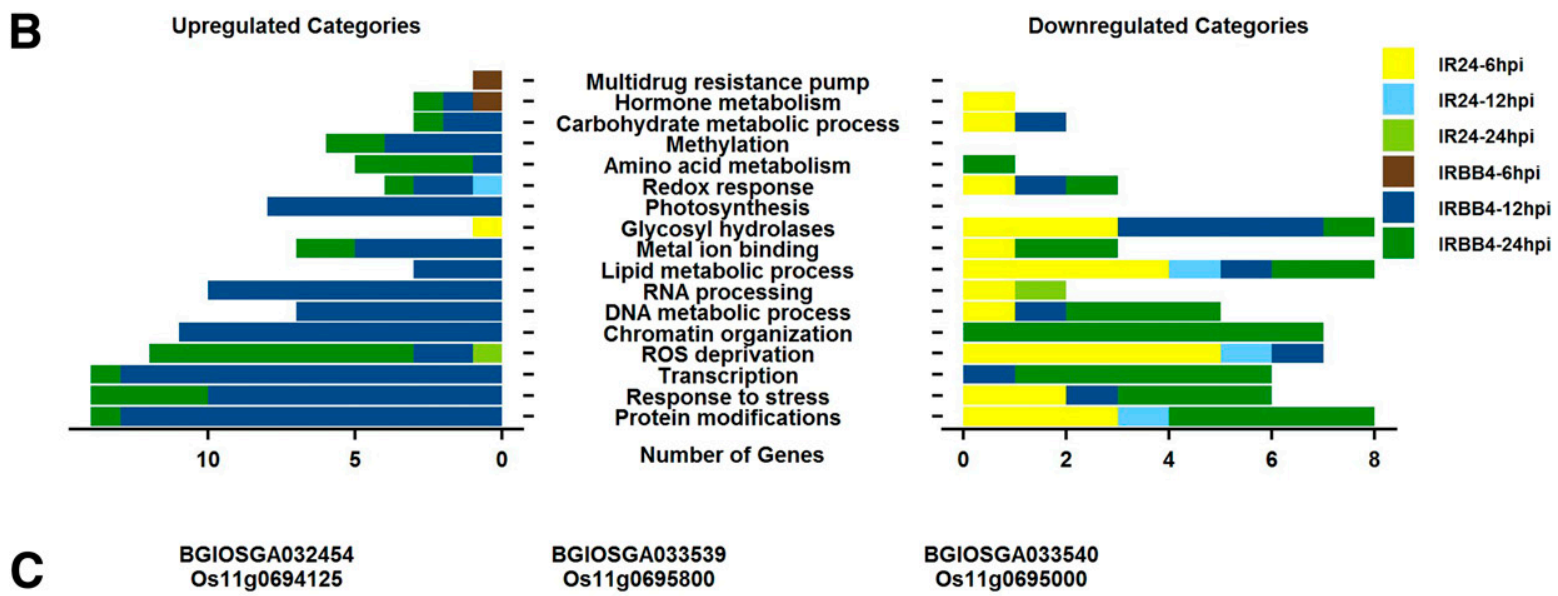

BGIOSGA033539
Os11g0695800

BGIOSGA033540
Os11g0695000
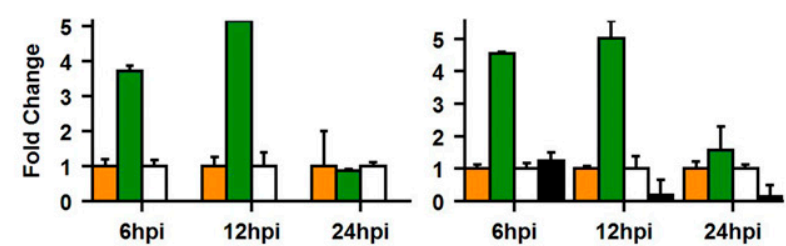

D

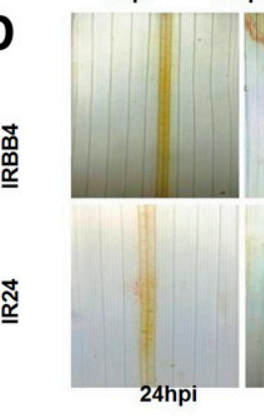

$\mathbf{F}$

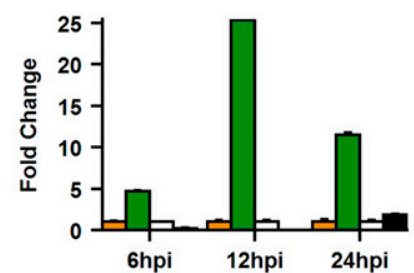

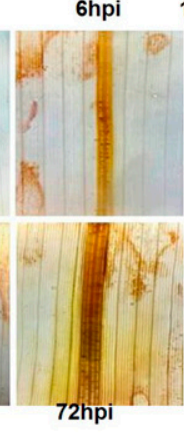

Os06g0486900

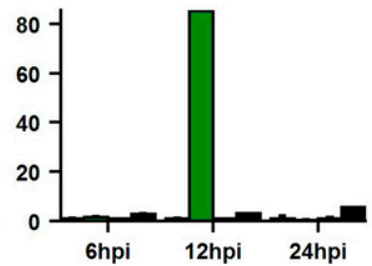

E

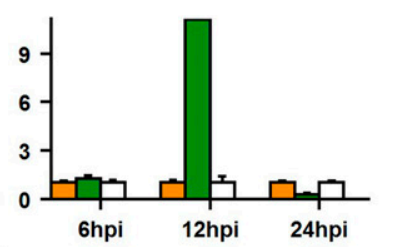

E
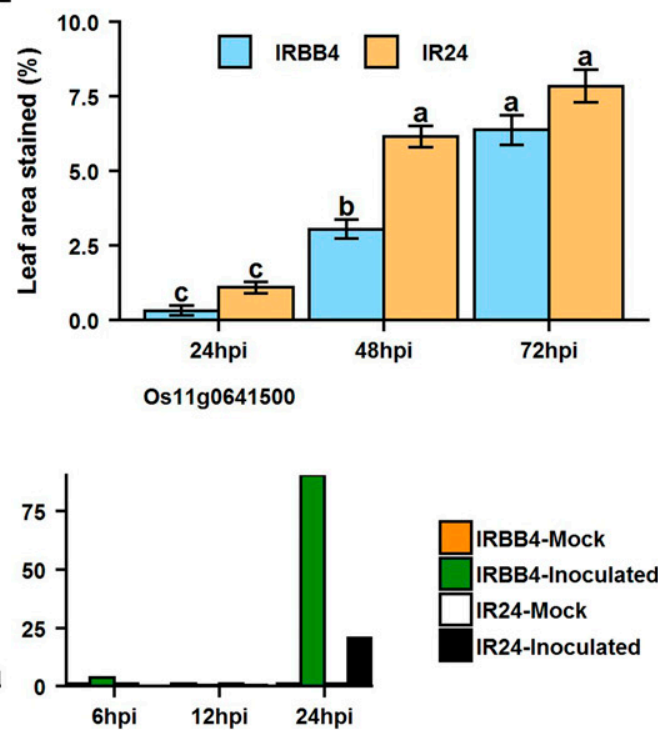

IRBB4-Mock

IRBB4-Inoculated

IR24-Mock

IR24-Inoculated

Fig. 4. Validation of $q L N 11^{28}$ contribution to sheath blight resistance. A, Sheath blight assessment of IR24 and near-isogenic line IRBB4 carrying a major quantitative trait locus using the detached tiller assay. Lesion numbers, maximum lesion length, and vertical sheath colonization were measured 7 days after inoculation. Swarna and ShB6 lines represent susceptible and resistant checks, respectively. B, Comparison of differentially expressed genes (DEGs) between IR24 and IRBB4 infected with Rhizoctonia solani at 6, 12, and $24 \mathrm{~h}$ postinoculation (hpi). Bars correspond to the number of genes upregulated (left) or downregulated (right) that show enrichment on biological process, cellular component, and molecular function (center). ROS = reactive oxygen species. DEGs with $>$ fivefold $=$ upregulated and $<$ fivefold $=$ downregulated. C, Transcript accumulation of selected genes in the $q L N 11^{28}$ region during a time course infection experiment in mock and inoculated plants of IRBB4 and IR24. D, ROS detection using 3,3'-diaminobenzidine (DAB) in response to pathogen infection. DAB staining of mock and inoculated leaves of IRBB4 and IR24 at 24, 48, and 72 hpi. E, Percentage of leaf area stained showing $\mathrm{H}_{2} \mathrm{O}_{2}$ accumulation in IRBB4 (blue) and IR24 (orange) measured at 24, 48, and $72 \mathrm{hpi}$. Bars show standard error of the mean (SEM). Means having the same letter have no significant differences according to the honestly significant difference test at $P<0.05$. F, Transcript accumulation of ROS recycling genes during a time course infection experiment in mock and inoculated plants of IRBB4 and IR24. A vertical line on each bar represents the SEM among three replicates (C and F). 
resistant line at $12 \mathrm{hpi}$ in both $0 s 05 \mathrm{~g} 0555600$ (25.35-fold) and Os06g0486900 (85.2-fold) and at $24 \mathrm{hpi}$ in Os11g0641500 (90.2-fold). The differences in transcript profiles of immune component and ROS deregulation indicate that the resistant line might respond faster and more efficiently modulate ROS production to stop pathogen colonization.

\section{DISCUSSION}

The study of complex traits is challenging because the phenotype is controlled by minor-effect genes usually affected by plant background or environmental condition. In this context, GWAS has become a powerful tool to analyze quantitative genetic factors in complex agricultural traits. $\mathrm{ShB}$ is a suitable target for GWAS because it is a complex disease with an economic impact in most rice-producing areas. In this study, we used 700,000 SNPs to identify five potential loci controlling $\mathrm{ShB}$ resistance in a diverse indica rice panel. We were able to validate one of these regions $\left(q L N 11^{28}\right)$ using a near-isogenic line and explore the potential mechanism behind the resistance. Our data suggest that the line carrying $q L N 11^{28}$ activates an early response and is able to modulate oxidative burst to prevent pathogen colonization.

In the last few years, GWAS has yielded very promising results by capturing novel loci for disease resistance (Gurung et al. 2014; Kump et al. 2011; Wen et al. 2014). In contrast to conventional mapping, the resolution is not affected by the amount of recombination nor is it limited by the reduced number of alleles present in parental lines. In that sense, this approach is able to capture underrepresented alleles (Weigel 2012) and accelerate the selection of allele combinations within donors that are fitted to targeted environments (Zhao et al. 2011). However, factors such as phenotypic variance, population size, and substructuring of the population can also affect the GWAS resolution (Korte and Farlow 2013). Our results suggest that $\mathrm{ShB}$ resistance in this population is controlled by many low-frequency variants with small to moderate phenotypic effects. It is important to note that most of the identified SNPs may not be causative of the effect but associated due to linkage with high heritability (Korte and Farlow 2013).

ShB studies that have utilized traditional mapping approaches have reported a number of QTLs contributing to resistance (Channamallikarjuna et al. 2010; Dey et al. 2016; Li et al. 1995; Liu et al. 2009; Pan et al. 1999; Pinson et al. 2005; TaguchiShiobara et al. 2013; Yadav et al. 2015; Zhu et al. 2014; Zou et al. 2000). Similar to other traits, ShB severity estimates may be affected by plant growth. In fact, several reports have identified ShB resistance QTLs colocalizing with loci for plant height or heading date (Channamallikarjuna et al. 2010; Li et al. 1995; Pan et al. 1999; Pinson et al. 2005; Zou et al. 2000). By using a diversity panel tested in DTA, no significant correlations between LC and any of the three disease components were obtained, suggesting that most of the signals observed in this study are not likely to colocalize with genes affecting either morphology or plant architecture. However, when exposed to microfield conditions, half of the identified tolerant accessions became susceptible. This observation aligns with previous reports (Lore et al. 2013; Srinivasachary et al. 2010, 2013; Willocquet et al. 2011) and suggests an additive genetic effect, in which environmental factors may interact differentially with each of the regions contributing to resistance and modulate plant response to $R$. solani in a genotype-specific manner.

We reported a total of five potential regions in this study, of which two major regions have significant SNPs controlling ShB resistance distributed in chromosome 11. Significant signals associated with $\operatorname{LN}\left(q L N 11^{28}\right)$ and $\operatorname{MLL}\left(q M L L 11^{14}\right)$, as well as regions with building signals associated with $\operatorname{VSC}\left(q V S C 1^{05}\right.$, $q V S C 4^{01}$, and $q V S C 11^{28}$ ), appeared to contribute small to moderate effects under DTA experiments. One of these signals corresponding to the LN component was located near the QTL $q S B 11^{H J X 74}$, which was previously identified by $\mathrm{Zhu}$ et al. (2014). This observation provided an independent validation of the detection power of $q L N 11^{28}$ using GWAS. Interestingly, the physical position of $q L N 11^{28}$ in chromosome 11 colocalized with a region enriched with defense-related genes, including the bacterial blight resistance genes $\mathrm{Xa} 4$ (Delteil et al. 2016; Kim et al. 2015), Xa3/Xa26 (Xiang et al. 2006), and Xa40 (Kim et al. 2015), among others. This region was introgressed from the Indian rice cultivar TKM6 into modern rice varieties (Mackill and Khush 2018), including IR64 and IRBB4. Therefore, we hypothesized that the factor contributing to ShB resistance within $q L N 11^{28}$ was transferred together with that particular locus during modern breeding. Interestingly, IRBB4 showed a significant reduction in LN compared with the parental background (IR24), suggesting that the QTL at chromosome 11 contributes, at least partially, to reduce disease spread under controlled conditions.

Our data suggest transcriptional reprogramming of plant defense components in IRBB4 associated with earlier response upon pathogen attack. Similar results have been reported in other resistant rice varieties infected with $R$. solani (Yuan et al. 2018; Zhang et al. 2017). It is likely that the $q L N 11^{28}$ region, which harbors a number of receptor-like genes and positive regulators, contains a gene or genes responsible for sensing the $R$. solani epitopes and activating faster signaling cascades. Moreover, the three genes that show differential expression in this region have defense-related features and may allow early activation of resistance. For instance, wall-associated kinases (WAK) are known to be sensors of pectin degradation during pathogen attack in Arabidopsis and rice (Kohorn and Kohorn 2012), and have been also associated with resistance to bacterial blight, $\mathrm{ShB}$, and blast in rice (Delteil et al. 2016; Hu et al. 2017; Kim et al. 2015; Yuan et al. 2018). If the $q L N 11^{28}$ region indeed harbors variants with different expression patterns, then a different reaction against $R$. solani may be linked.

Transcriptional reprogramming associated with $q L N 11^{28}$ also involves the activation of a number of genes related to the ROS-redox pathway. This mechanism controls the amount of subcellular ROS that might have evolved to maintain a tide regulation of ROS's signaling role (Noctor et al. 2018). Consistent with this observation, histochemical staining also suggests that the resistant line IRBB4 accumulates less ROS compared with the susceptible IR24. This was also reported in resistant plants infected with the necrotrophic pathogens Botrytis cinerea and Sclerotinia sclerotiorum (Govrin and Levine 2000; Kużniak and Skłodowska 2005). In this case, the pathogen stimulates plant ROS production to induce cell death that will allow fungal growth and the colonization of more cells which are necessary for Rhizoctonia spp. to complete the infection cycle. It could aid as a conducive area for the establishment phase of the pathogen toward a successive necrotrophic phase. In other cases, ROS accumulation has been suggested as a resistance mechanism for necrotrophic and biotrophic fungi. Therefore, ROS should be considered a complex response not necessarily linked to a particular interaction. For $\mathrm{ShB}$, it can be speculated that resistance might be related to the activation of a ROS recycling system that impedes $R$. solani colonization. Studies of gene expression provide information about differences in gene expression between samples and time points. Results of the RT-qPCR verification for the $q L N 11^{28}$ region and the ROS recycling genes provide information related to complex regulatory networks and interactions between hosts and pathogens. It is highly likely that these genes are good candidates in developing markers linked 
with $q L N 11^{28}$. The Os05g0555600 gene is associated with ammonium pathways that reduce ammonium as a signal in the regulation of ROS. Os06g0486900 is related to stress response after ROS is reduced. Meanwhile, $O s 11 \mathrm{~g} 0641500$ is a laccase gene that is produced by fungus and acts as a delaying defense response in regulating ROS accumulation in the chloroplast and mitochondria. The DEGs at the $q L N 11^{28}$ (Os 1 1g0694125, Os 11 0695800, and Os11g0695000) region are receptor-like kinases and play important roles in regulating growth, development, and stress responses in plants. Among the $q L N 11^{28}$ genes, Os11g0694125 and Os11g0695000 are considered candidate genes because they were not expressed in the susceptible line IR24. In particular, Os11g0694125 encodes a wall-associated receptor kinase and galacturonan-binding domains that are involved in the basal defense response of plants. Meanwhile, Os11g0695000 encodes for leucine-rich protein kinase, which is considered to be the first line of defense where the innate immune response is initiated through sensing of pathogen-associated molecular patterns and provides recognition of pathogen products.

Similar to $q L N 11^{28}$, the GWAS signals under $q M L L 11^{14}$, $q V S C 1^{05}, q V S C 4^{01}$, and $q V S C 11^{28}$ are also enriched in defenserelated and signal transduction genes. For instance, several nucleotide-binding site leucine-rich repeat (LRR) proteins such as homologs of the stripe rust resistance protein Yr10 (Liu et al. 2014) were found in this region. The NB-ARC domaincontaining protein (van Ooijen et al. 2008), LRR family protein (de Wit et al. 2011), OsWAK29 receptor-like protein kinases (Delteil et al. 2016), and zinc finger (Gupta et al. 2012) are some of the homologs identified in these regions. Interestingly, the presence of common defense resistance genes in the $q L N 11^{28}$ and $q V S C 11^{28}$ regions was also noted. These data might suggest that natural variants of other defense-related genes might also be contributing to disease resistance. In general, most of the signals identified in this study appear to have small to moderate effects on the expression of disease symptoms. In addition to this limitation, we were able to distinguish different resistance factors, which highlight the value of diversity panels for dissecting complex traits. A diversity panel is a valuable resource for the dissection of complex traits because it provides a higher mapping resolution and allows the capture of small variations in common genes.

In this study, the quantitative disease response to $\mathrm{ShB}$ allowed us to identify five genomic regions that contribute partially to resistance. We were able to isolate one of these regions, which seems to be the key element in basal immune responses. We predict that stacking multiple genes might have additive genetic effects that would enhance durable ShB resistance and might help to reduce the use of chemical control. Overall, our findings highlight the importance of utilizing adequate donors to improve modern rice varieties in areas where the $\mathrm{ShB}$ disease is prevalent.

\section{MATERIALS AND METHODS}

\section{Plant materials.}

In total, 240 rice accessions were used to explore the wide variation of susceptibility to $\mathrm{ShB}$ disease. First, we randomly selected 10 diverse rice lines for the initial DTA experiment and another 228 indica rice accessions were used for GWAS. These lines were derived from a diversity panel with 1,568 entries available at the International Rice Genebank Collection (Supplementary Table S1). In addition to these lines, Swarna and ShB6 (O. rufipogon-derived line) were also included as susceptible and resistant checks, respectively. For validation of a candidate signal and transcriptome analysis, we used the indica variety IR24 and its near-isogenic line IRBB4.

\section{Phenotypic evaluation.}

The two sets of rice lines were phenotyped through DTA, as described by Willocquet et al. (2011). At maximum tillering stage, the detached main tillers were inoculated by transferring a 1-week-old $R$. solani strain LR-1 sclerotium on the inner side of the leaf collar, second from the topmost leaf sheath. To determine the plant response to ShB, we measured three disease components (LN, MLL, and VSC) at 7 dpi. For microfield evaluation, we verified the levels of resistance and susceptibility among the selected rice accessions from the DTA by performing the modified microfield experiment, as previously described by Srinivasachary et al. (2013). Rice plants at maximum tillering stage were inoculated at the base of the hill through a colonized mixture of $R$. solani and rice grain rice hull. The microfield experiment was conducted in a screenhouse containing concrete beds filled with soil under semifield conditions. The whole microfield setup was continuously misted for $10 \mathrm{~min}$ at intervals of 3 to 4 hpi until the disease assessment. The water level in the microfield was kept just above soil level throughout the last experiment. Weather data were collected daily from inoculation until the assessment day using a datalogger (HOBO, U23 Pro v2 temperature/relative humidity data logger; Onset Computer Corporation, Bourne, MA, U.S.A.). The microfield experiment was established according to randomized complete block design with three replications and was phenotyped for four disease parameters: LN, MLL, lesion height, and tiller incidence (Supplementary Table S2). We performed ANOVA for the phenotypic data with SAS (SAS 9.2; SAS Institute Inc., Cary, NC, U.S.A.) using contrast analysis (data not shown).

\section{Genotypic analysis.}

The genotype data of the 228 indica accessions were obtained using HDRA with 700,000 SNPs (McCouch et al. 2016). The final genotype dataset comprising 213,699 SNPs was generated after removing all monomorphic SNPs with call rates $<80 \%$ and SNPs with minor allele frequencies $<0.05$ across all samples. For the phylogenetic analysis, a neighborjoining tree of the 228 indica accessions was constructed based on Nei's genetic distance using Trait Analysis by Association, Evolution and Linkage (TASSEL), version 5.2.38 (Bradbury et al. 2007), and a graphical visualization of the phylogenetic tree was made using Interactive Tree Of Life, version 4.2.3 (Letunic and Bork 2016). To infer the population stratification of selected indica accessions, we conducted principal component analysis (PCA) in TASSEL to build up the $P$ matrix for the population structure correction.

\section{Genome-wide association mapping.}

The mixed linear model (MLM) method was used to test the associations between the phenotypic and genotypic data and to control spurious positives in GWAS. The MLM analysis considers the SNP dataset as a fixed effect and includes PCA and relative kinship matrices as random effects in the method. Based on the same set of SNPs, the population structure and kinship matrices were calculated to determine the relatedness among individuals using TASSEL. The Manhattan and QQ plots were performed using the package QQman in R. We used a threshold of $-\log _{10} P \geq 6.63$ based on Bonferroni correction ( $\alpha=0.05)$ to detect significant signals among the disease components.

\section{LD pattern and candidate genes associated to $\mathrm{ShB}$ resistance.}

To estimate LD decay in rice, we measured the square of the correlation coefficient $\left(r^{2}\right)$ using TASSEL to determine the correlation in frequency among pairs of alleles across the major peaks for each disease component. Haplotype block determination and 
visualization were carried out with Haploview (4.1) (Barrett et al. 2005). We searched genes within the 200-kb region upstream and downstream of the five putative regions which could probably be the candidate genes for these associations. Selected regions were searched using the IRRI-GSL Galaxy, a specialized deployment of Galaxy at IRRI.

\section{Transcriptome analysis.}

To understand the contribution of a single QTL on the transcriptional reprogramming of rice during $R$. solani infection, we performed RNA sequencing (RNA-seq) of IR24 and its near-isogenic line IRBB4. At maximum tillering stage, rice sheaths were inoculated following the procedure described by Willocquet et al. (2011) by inserting a single sclerotium (or water, in the case of mock plants) beneath the leaf sheath. Tissues were collected 6, 12, and 24 hpi. Total RNA was then treated with DNase (Promega Corp., Madison, WI, U.S.A.) and integrity was checked using an Agilent 2100 Bioanalyzer (Agilent Technologies, Santa Clara, CA, U.S.A.). For each time point, three replicates were prepared. A 100-bp paired-end library was prepared and sequenced with the BGISEQ-500 platform (BGI, China). To capture the overall transcription profile of plants, the clean reads were mapped to two reference genomes using the Subread package in R (Liao et al. 2013). The reference genomes were $O$. sativa subsp. japonica 'Nipponbare' (assembly Build 4.0; NCBI) and $O$. sativa subsp. indica '93-11' (ASM465v1). The count-per-million normalization and differential expression analysis were done with the EdgeR package (Robinson et al. 2010). DEGs were selected by comparing infected over mock samples from the same time point. Reads with $P$ value $<0.05$, false discovery rate $<0.05$, and a twofold change were kept. For gene ontology analysis, we used Biomart (Durinck et al. 2009). To detect indirect interactions and predominant pathways in our DEGs, we used the tool RiceNet v2 (Lee et al. 2015). To investigate specific changes in the single QTL, we used a 167-kb scaffold of the IR64 draft genome (Os-IR64-Draft-CSHL-1.0). To study the gene expression and validate the candidate genes obtained from the RNA-seq, RT-qPCR was employed on the $R$. solaniinfected IR24 and IRBB4. The RT-qPCR was performed on Applied Biosystems Step One Plus RT-PCR system using the SYBR Green Master Mix (Thermo Fisher Scientific). The rice gene Actin was used as internal control. The average threshold cycle was used to determine the fold change of the mRNA level. Each RT-qPCR was conducted in technical triplicate.

\section{ROS assay.}

Detection of ROS accumulation was done using 3,3' diaminobenzidine (DAB) staining as described (Daudi and O'Brien 2012), with some modifications. Briefly, 10 leaf segments (approximately $2 \mathrm{~cm}$ ) per time point were cut from the youngest leaf of 4-week-old plants and placed in a petri plate. A $R$. solani mycelial disc ( $3 \mathrm{~mm}$ in diameter) was placed at the middle of each detached leaf. After 24, 48, and $72 \mathrm{hpi}$, the leaf segments were immersed in 2-ml DAB-HCL solutions $(1 \mathrm{mg} / \mathrm{ml})$ prepared in double-distilled water $(2 \mathrm{ml})(\mathrm{pH} 3.8)$ and the samples were incubated overnight at room temperature under light. Following staining, the leaves were bleached in acetic acid-glycerol-ethanol $(1: 1: 3$ [vol/vol] $)$ solution at $65^{\circ} \mathrm{C}$ for $1 \mathrm{~h}$ to remove chlorophyll and were stored in glycerolethanol $(1: 4$ [vol/vol] $)$ solution. $\mathrm{H}_{2} \mathrm{O}_{2}$ was visualized as a reddish-brown coloration (Thordal-Christensen et al. 1997) under an Olympus stereo SZX7 microscope. Stained areas were quantified using Image $\mathbf{J}$ software and statistically analyzed using the Statistical Tool for Agricultural Research (STAR 2.0.1) software.

\section{ACKNOWLEDGMENTS}

We thank E. Silab, E. Pizarra, M. Carillaga, and I. Mamiit for their assistance in performing the phenotyping experiment; and S. Dossa for technical assistance.

\section{LITERATURE CITED}

Asselbergh, B., Curvers, K., Franca, S. C., Audenaert, K., Vuylsteke, M., Van Breusegem, F., and Höfte, M. 2007. Resistance to Botrytis cinerea in sitiens, an abscisic acid-deficient tomato mutant, involves timely production of hydrogen peroxide and cell wall modifications in the epidermis. Plant Physiol. 144:1863-1877.

Bandillo, N., Raghavan, C., Muyco, P. A., Sevilla, M. A. L., Lobina, I. T., Dilla-Ermita, C. J., Tung, C.-W., McCouch, S., Thomson, M., Mauleon, R., Singh, R. K., Gregorio, G., Redoña, E., and Leung, H. 2013. Multiparent advanced generation inter-cross (MAGIC) populations in rice: Progress and potential for genetics research and breeding. Rice 6:11.

Barrett, J. C., Fry, B., Maller, J., and Daly, M. J. 2005. Haploview: Analysis and visualization of LD and haplotype maps. Bioinformatics 21: 263-265.

Begum, H., Spindel, J. E., Lalusin, A., Borromeo, T., Gregorio, G., Hernandez, J., Virk, P., Collard, B., and McCouch, S. R. 2015. Genomewide association mapping for yield and other agronomic traits in an elite breeding population of tropical rice (Oryza sativa). PLoS One 10: e0119873.

Bradbury, P. J., Zhang, Z., Kroon, D. E., Casstevens, T. M., Ramdoss, Y., and Buckler, E. S. 2007. TASSEL: Software for association mapping of complex traits in diverse samples. Bioinformatics 23:2633-2635.

Channamallikarjuna, V., Sonah, H., Prasad, M., Rao, G. J. N., Chand, S., Upreti, H. C., Singh, N. K., and Sharma, T. R. 2010. Identification of major quantitative trait loci $q S B R 11-1$ for sheath blight resistance in rice. Mol. Breed. 25:155-166.

Crowell, S., Korniliev, P., Falcão, A., Ismail, A., Gregorio, G., Mezey, J., and McCouch, S. 2016. Genome-wide association and high-resolution phenotyping link Oryza sativa panicle traits to numerous trait-specific QTL clusters. Nat. Commun. 7:10527.

Daudi, A., and O'Brien, J. A. 2012. Detection of hydrogen peroxide by DAB staining in Arabidopsis leaves. Bio Protoc. 2:e263.

Delteil, A., Gobbato, E., Cayrol, B., Estevan, J., Michel-Romiti, C., Dievart, A., Kroj, T., and Morel, J.-B. 2016. Several wall-associated kinases participate positively and negatively in basal defense against rice blast fungus. BMC Plant Biol. 16:17.

de Wit, J., Hong, W., Luo, L., and Ghosh, A. 2011. Role of leucine-rich repeat proteins in the development and function of neural circuits. Annu. Rev. Cell Dev. Biol. 27:697-729.

Dey, S., Badri, J., Prakasam, V., Bhadana, V. P., Eswari, K. B., Laha, G. S., Priyanka, C., Rajkumar, A., and Ram, T. 2016. Identification and agromorphological characterization of rice genotypes resistant to sheath blight. Australas. Plant Pathol. 45:145-153.

Durinck, S., Spellman, P. T., Birney, E., and Huber, W. 2009. Mapping identifiers for the integration of genomic datasets with the R/Bioconductor package biomaRt. Nat. Protoc. 4:1184-1191.

Ghosh, S., Kanwar, P., and Jha, G. 2017. Alterations in rice chloroplast integrity, photosynthesis and metabolome associated with pathogenesis of Rhizoctonia solani. Sci. Rep. 7:41610.

Govrin, E. M., and Levine, A. 2000. The hypersensitive response facilitates plant infection by the necrotrophic pathogen Botrytis cinerea. Curr. Biol 10:751-757.

Gupta, S. K., Rai, A. K., Kanwar, S. S., and Sharma, T. R. 2012. Comparative analysis of zinc finger proteins involved in plant disease resistance. PLoS One 7:e42578.

Gurung, S., Mamidi, S., Bonman, J. M., Xiong, M., Brown-Guedira, G., and Adhikari, T. B. 2014. Genome-wide association study reveals novel quantitative trait loci associated with resistance to multiple leaf spot diseases of spring wheat. PLoS One 9:e108179.

Hossain, M. K., Tze, O. S., Nadarajah, K., Jena, K., Rahman Bhuiyan, M. A., and Ratnam, W. 2014. Identification and validation of sheath blight resistance in rice (Oryza sativa L.) cultivars against Rhizoctonia solani. Can. J. Plant Pathol. 36:482-490.

Hu, K., Cao, J., Zhang, J., Xia, F., Ke, Y., Zhang, H., Xie, W., Liu, H., Cui, Y., Cao, Y., Sun, X., Xiao, J., Li, X., Zhang, Q., and Wang, S. 2017. Improvement of multiple agronomic traits by a disease resistance gene via cell wall reinforcement. Nat. Plants 3:17009.

Huang, X., Wei, X., Sang, T., Zhao, Q., Feng, Q., Zhao, Y., Li, C., Zhu, C., Lu, T., Zhang, Z., Li, M., Fan, D., Guo, Y., Wang, A., Wang, L., Deng, L., Li, W., Lu, Y., Weng, Q., Liu, K., Huang, T., Zhou, T., Jing, Y., Li, W., 
Lin, Z., Buckler, E. S., Qian, Q., Zhang, Q.-F., Li, J., and Han, B. 2010. Genome-wide association studies of 14 agronomic traits in rice landraces. Nat. Genet. 42:961-967.

Jia, L., Yan, W., Zhu, C., Agrama, H. A., Jackson, A., Yeater, K., Li, X., Huang, B., Hu, B., McClung, A., and Wu, D. 2012. Allelic analysis of sheath blight resistance with association mapping in rice. PLoS One 7: e32703.

Kim, S.-M., Suh, J.-P., Qin, Y., Noh, T.-H., Reinke, R. F., and Jena, K. K. 2015. Identification and fine-mapping of a new resistance gene, Xa40, conferring resistance to bacterial blight races in rice (Oryza sativa L.). Theor. Appl. Genet. 128:1933-1943.

Kohorn, B. D., and Kohorn, S. L. 2012. The cell wall-associated kinases, WAKs, as pectin receptors. Front. Plant Sci. 3:88.

Korte, A., and Farlow, A. 2013. The advantages and limitations of trait analysis with GWAS: A review. Plant Methods 9:29.

Kump, K. L., Bradbury, P. J., Wisser, R. J., Buckler, E. S., Belcher, A. R., Oropeza-Rosas, M. A., Zwonitzer, J. C., Kresovich, S., McMullen, M. D., Ware, D., Balint-Kurti, P. J., and Holland, J. B. 2011. Genomewide association study of quantitative resistance to southern leaf blight in the maize nested association mapping population. Nat. Genet. 43: 163-168.

Kużniak, E., and Skłodowska, M. 2005. Fungal pathogen-induced changes in the antioxidant systems of leaf peroxisomes from infected tomato plants. Planta 222:192-200.

Lee, T., Oh, T., Yang, S., Shin, J., Hwang, S., Kim, C. Y., Kim, H., Shim, H., Shim, J. E., Ronald, P. C., and Lee, I. 2015. RiceNet v2: An improved network prioritization server for rice genes. Nucleic Acids Res. 43: W122-W127.

Letunic, I., and Bork, P. 2016. Interactive tree of life (iTOL) v3: An online tool for the display and annotation of phylogenetic and other trees. Nucleic Acids Res. 44:W242-W245.

Li, Z., Pinson, S. R., Marchetti, M. A., Stansel, J. W., and Park, W. D. 1995. Characterization of quantitative trait loci (QTLs) in cultivated rice contributing to field resistance to sheath blight (Rhizoctonia solani). Theor. Appl. Genet. 91:382-388.

Liao, Y., Smyth, G. K., and Shi, W. 2013. The Subread aligner: Fast, accurate and scalable read mapping by seed-and-vote. Nucleic Acids Res. 41:e108.

Liu, G., Jia, Y., Correa-Victoria, F. J., Prado, G. A., Yeater, K. M., McClung, A., and Correll, J. C. 2009. Mapping quantitative trait Loci responsible for resistance to sheath blight in rice. Phytopathology 99:1078-1084.

Liu, W., Frick, M., Huel, R., Nykiforuk, C. L., Wang, X., Gaudet, D. A., Eudes, F., Conner, R. L., Kuzyk, A., Chen, Q., Kang, Z., and Laroche, A. 2014. The stripe rust resistance gene YrlO encodes an evolutionaryconserved and unique CC-NBS-LRR sequence in wheat. Mol. Plant 7: 1740-1755

Lore, J. S., Hunjan, M. S., Singh, P., Willocquet, L., Sri, S., and Savary, S. 2013. Phenotyping of partial physiological resistance to rice sheath blight. J. Phytopathol. 161:224-229.

Mackill, D. J., and Khush, G. S. 2018. IR64: A high-quality and highyielding mega variety. Rice 11:18.

Mather, K. A., Caicedo, A. L., Polato, N. R., Olsen, K. M., McCouch, S., and Purugganan, M. D. 2007. The extent of linkage disequilibrium in rice (Oryza sativa L.). Genetics 177:2223-2232.

McCouch, S. R., Wright, M. H., Tung, C.-W., Maron, L. G., McNally, K. L., Fitzgerald, M., Singh, N., DeClerck, G., Agosto-Perez, F., Korniliev, P., Greenberg, A. J., Naredo, M. E. B., Mercado, S. M. Q., Harrington, S. E., Shi, Y., Branchini, D. A., Kuser-Falcão, P. R., Leung, H., Ebana, K., Yano, M., Eizenga, G., McClung, A., and Mezey, J. 2016. Open access resources for genome-wide association mapping in rice. Nat. Commun. 7:10532.

McNally, K. L., Childs, K. L., Bohnert, R., Davidson, R. M., Zhao, K., Ulat, V. J., Zeller, G., Clark, R. M., Hoen, D. R., Bureau, T. E., Stokowski, R., Ballinger, D. G., Frazer, K. A., Cox, D. R., Padhukasahasram, B., Bustamante, C. D., Weigel, D., Mackill, D. J., Bruskiewich, R. M., Rätsch, G., Buell, C. R., Leung, H., and Leach, J. E. 2009. Genomewide SNP variation reveals relationships among landraces and modern varieties of rice. Proc. Natl. Acad. Sci. U.S.A. 106:12273-12278.

Myles, S., Peiffer, J., Brown, P. J., Ersoz, E. S., Zhang, Z., Costich, D. E., and Buckler, E. S. 2009. Association mapping: Critical considerations shift from genotyping to experimental design. Plant Cell 21: 2194-2202.

Noctor, G., Reichheld, J.-P., and Foyer, C. H. 2018. ROS-related redox regulation and signaling in plants. Semin. Cell Dev. Biol. 80:3-12.

$\mathrm{Ou}, \mathrm{S}$. H. 1985. Rice Diseases. CAB International Mycological Institute, Wallingford, Oxfordshire, U.K

Pan, X. B., Rush, M. C., Sha, X. Y., Xie, Q. J., Linscombe, S. D., Stetina, S. R., and Oard, J. H. 1999. Major gene, nonallelic sheath blight resistance from the rice cultivars Jasmine 85 and Teqing. Crop Sci. 39: 338-346.

Pasam, R. K., Sharma, R., Malosetti, M., van Eeuwijk, F. A., Haseneyer, G., Kilian, B., and Graner, A. 2012. Genome-wide association studies for agronomical traits in a world wide spring barley collection. BMC Plant Biol. 12:16.

Pinson, S. R. M., Capdevielle, F. M., and Oard, J. H. 2005. Confirming QTLs and finding additional loci conditioning sheath blight resistance in rice using recombinant inbred lines. Crop Sci. 45:503-510.

Qian, L., Hickey, L. T., Stahl, A., Werner, C. R., Hayes, B., Snowdon, R. J., and Voss-Fels, K. P. 2017. Exploring and harnessing haplotype diversity to improve yield stability in crops. Front. Plant Sci. 8:1534.

Robinson, M. D., McCarthy, D. J., and Smyth, G. K. 2010. edgeR: A Bioconductor package for differential expression analysis of digital gene expression data. Bioinformatics 26:139-140.

Savary, S., Ficke, A., Aubertot, J.-N., and Hollier, C. 2012. Crop losses due to diseases and their implications for global food production losses and food security. Food Secur. 4:519-537.

Schneider, R., Rolling, W., Song, Q., Cregan, P., Dorrance, A. E., and McHale, L. K. 2016. Genome-wide association mapping of partial resistance to Phytophthora sojae in soybean plant introductions from the Republic of Korea. BMC Genomics 17:607.

Sharma, N. R., and Teng, P. S. 1990. Comparison of rice sheath blight ShB assessment methods. Int. Rice Res. Newsl. 15:20-21.

Srinivasachary, Beligan, G., Willocquet, L., and Savary, S. 2013. A strategy to identify sources of quantitative resistance in pathosystems involving disease escape and physiological resistance: The case study of rice sheath blight. Plant Pathol. 62:888-899.

Srinivasachary, Willocquet, L., and Savary, S. 2010. Resistance to rice sheath blight (Rhizoctonia solani Kühn) [(teleomorph: Thanatephorus cucumeris (A.B. Frank) Donk.] disease: Current status and perspectives. Euphytica 178:1-22.

Stracke, S., Presterl, T., Stein, N., Perovic, D., Ordon, F., and Graner, A. 2007. Effects of introgression and recombination on haplotype structure and linkage disequilibrium surrounding a locus encoding Bymovirus resistance in barley. Genetics 175:805-817.

Taguchi-Shiobara, F., Ozaki, H., Sato, H., Maeda, H., Kojima, Y., Ebitani, T., and Yano, M. 2013. Mapping and validation of QTLs for rice sheath blight resistance. Breed. Sci. 63:301-308.

Thordal-Christensen, H., Zhang, Z., Wei, Y., and Collinge, D. B. 1997. Subcellular localization of $\mathrm{H}_{2} \mathrm{O}_{2}$ in plants. $\mathrm{H}_{2} \mathrm{O}_{2}$ accumulation in papillae and hypersensitive response during the barley-powdery mildew interaction. Plant J. 11:1187-1194.

van Ooijen, G., Mayr, G., Kasiem, M. M. A., Albrecht, M., Cornelissen, B. J. C., and Takken, F. L. W. 2008. Structure-function analysis of the NB-ARC domain of plant disease resistance proteins. J. Exp. Bot. 59: 1383-1397.

Vuong, T. D., Sonah, H., Meinhardt, C. G., Deshmukh, R., Kadam, S., Nelson, R. L., Shannon, J. G., and Nguyen, H. T. 2015. Genetic architecture of cyst nematode resistance revealed by genome-wide association study in soybean. BMC Genomics 16:593.

Wang, C., Yang, Y., Yuan, X., Xu, Q., Feng, Y., Yu, H., Wang, Y., and Wei, X. 2014. Genome-wide association study of blast resistance in indica rice. BMC Plant Biol. 14:311.

Weigel, D. 2012. Natural variation in Arabidopsis: From molecular genetics to ecological genomics. Plant Physiol. 158:2-22.

Wen, Z., Tan, R., Yuan, J., Bales, C., Du, W., Zhang, S., Chilvers, M. I., Schmidt, C., Song, Q., Cregan, P. B., and Wang, D. 2014. Genome-wide association mapping of quantitative resistance to sudden death syndrome in soybean. BMC Genomics 15:809.

Willocquet, L., Lore, J. S., Srinivasachary, S., and Savary, S. 2011. Quantification of the components of resistance to rice sheath blight using a detached tiller test under controlled conditions. Plant Dis. 95: 1507-1515.

Xiang, Y., Cao, Y., Xu, C., Li, X., and Wang, S. 2006. Xa3, conferring resistance for rice bacterial blight and encoding a receptor kinase-like protein, is the same as Xa26. Theor. Appl. Genet. 113:1347-1355.

Xu, Q., Yuan, X., Wang, S., Feng, Y., Yu, H., Wang, Y., Yang, Y., Wei, X., and $\mathrm{Li}, \mathrm{X}$. 2016. The genetic diversity and structure of indica rice in China as detected by single nucleotide polymorphism analysis. BMC Genet. 17:53.

Yadav, S., Anuradha, G., Kumar, R. R., Vemireddy, L. R., Sudhakar, R., Donempudi, K., Venkata, D., Jabeen, F., Narasimhan, Y. K., Marathi, B. and Siddiq, E. A. 2015. Identification of QTLs and possible candidate genes conferring sheath blight resistance in rice (Oryza sativa L.). SpringerPlus 4:175.

Yuan, Z., Zhang, Y., Xu, G., Bi, D., Qu, H., Zou, X., Gao, X., Yang, H., He, H., Wang, X., Bao, J., Zuo, S., Pan, X., Zhou, B., Wang, G.-L., and Qu, S. 
2018. Comparative transcriptome analysis of Rhizoctonia solaniresistant and -susceptible rice cultivars reveals the importance of pathogen recognition and active immune responses in host resistance. J. Plant Biol. 61:143-158.

Zeng, Y., Ji, Z., and Yang, C. 2015. The way to a more precise sheath blight resistance QTL in rice. Euphytica 203:33-45.

Zhang, J., Chen, L., Fu, C., Wang, L., Liu, H., Cheng, Y., Li, S., Deng, Q., Wang, S., Zhu, J., Liang, Y., Li, P., and Zheng, A. 2017. Comparative transcriptome analyses of gene expression changes triggered by Rhizoctonia solani AG1 IA infection in resistant and susceptible rice varieties. Front. Plant Sci. 8:1422.

Zhao, K., Tung, C.-W., Eizenga, G. C., Wright, M. H., Ali, M. L., Price, A. H., Norton, G. J., Islam, M. R., Reynolds, A., Mezey, J., McClung, A. M., Bustamante, C. D., and McCouch, S. R. 2011. Genome-wide association mapping reveals a rich genetic architecture of complex traits in Oryza sativa. Nat. Commun. 2:467.
Zhao, Y., Wang, H., Chen, W., and Li, Y. 2014. Genetic structure, linkage disequilibrium and association mapping of Verticillium wilt resistance in elite cotton (Gossypium hirsutum L.) germplasm population. PLoS One 9:e86308.

Zhu, Y., Zuo, S., Chen, Z., Chen, X., Li, G., Zhang, Y., Zhang, G., and Pan, $X$. 2014. Identification of two major rice sheath blight resistance QTLs, $q S B 1-1^{H J X 74}$ and $q S B 11^{H J X 74}$, in field trials using chromosome segment substitution lines. Plant Dis. 98:1112-1121.

Zou, J. H., Pan, X. B., Chen, Z. X., Xu, J. Y., Lu, J. F., Zhai, W. X., and Zhu, L. H. 2000. Mapping quantitative trait loci controlling sheath bligh resistance in two rice cultivars (Oryza sativa L.). Theor. Appl. Genet. 101:569-573.

Zuo, S., Zhang, L., Wang, H., Yin, Y., Zhang, Y., Chen, Z., Ma, Y., and Pan, X. 2008. Prospect of the $Q T L-q S B-9 T q$ utilized in molecular breeding program of japonica rice against sheath blight. J. Genet. Genomics 35: 499-505. 